\title{
Lumbar intraspinal extradural ganglion cyst
}

\author{
ADAM BRISH AND HUSHONG M. PAYAN \\ From the Department of Neurological Surgery and Department of Pathology, \\ St. Luke's Hospital, Marquette, Michigan, U.S.A.
}

SUMMARY A case is presented of an intraspinal extradural ganglion cyst at the L4-5 level. The clinical picture suggested a herniated nucleus pulposus at this level. A myelogram revealed a round lesion almost completely obstructing the flow of Pantopaque at the L4-5 level. A ganglion cyst with a haemorrhage into it and the surrounding tissue was removed, and surgery was followed by complete recovery.

A ganglionic cyst is a common 'tumour' found in the vicinity of joint capsules or tendon sheaths of the extremities. A rather unconventional location for a ganglion is the lumbar intraspinal extradural space. A haemorrhage into such a ganglion cyst is an even more unusual finding and no similar case could be found in the literature available to us.

In 1963 Gortvai accumulated 61 cases of extradural cyst of the spinal canal from the literature and this included his own five cases. In the majority of cases no communication with the subarachnoid space could be demonstrated. Not all of these had myelographic studies. Most of the cysts were found in the age group between 11 to 15 years and most were localized in the lower thoracic area. About half of them were connected with kyphosis. The author believed that most of the extradural cysts were congenital in origin but that some arose as the result of trauma.

Kao, Uihlein, Bickel, and Soule (1968) reported three ganglion cysts, all of which were at the L4-5 level. Two were intraspinal, extradural, and symptomatic, but the third was extraspinal, arising from the facet joint, and was found accidentally during disc surgery.

In the majority of patients from the literature, plain radiographs of the spinal column showed erosion of the pedicles or scalloping of the vertebral bodies (Coward and Bucy, 1937; Meredith, 1940; Gortvai, 1963; Krumholz, Hankowitz, and Schyra, 1966). Kao et al. (1968) found areas of circumscribed bony erosion with changes in the adjacent pedicle in a laminogram in one case. Meredith (1940) found haemosiderin in the cyst wall in one case with a previous history of injury. This was a cyst with arachnoid lining. Except for the cases published by Kao et al. (1968), none of the cystic lesions was diagnosed as ganglion cysts.

\section{CASE REPORT}

A 51 year old right-handed heavy equipment operator was admitted to St. Luke's Hospital in Marquette, Michigan, on 5 December 1970. He complained of low back pain, off and on, over the preceding 10 years. In the year before admission the patient noticed that the pain would at times radiate to the left hip. He was treated during this year with medication by his family physician. Three months before admission, the condition became progressively worse and the pain shifted more to the left lower extremity, radiating along the posterior aspect of the left thigh and lateral aspect of the left leg. At times, the patient would feel numbness in the left hallux. Coughing, sneezing, or straining would aggravate the condition. Bed rest would relieve some of the pain, but at night the pain usually became worse.

The past history revealed a sensation of burning in the testicles about 15 years ago. At that time he was operated on for what was diagnosed as varicocoele on the left side. About five years before admission the left testicle was removed after ' it became markedly swollen'. From time to time, the patient would have a burning sensation in the scrotum, but he was not aware of any connection between it and the backache. There was no history of any significant recent injury.

Examination revealed a well-built and wellnourished caucasian male, seen in bed, in no distress 


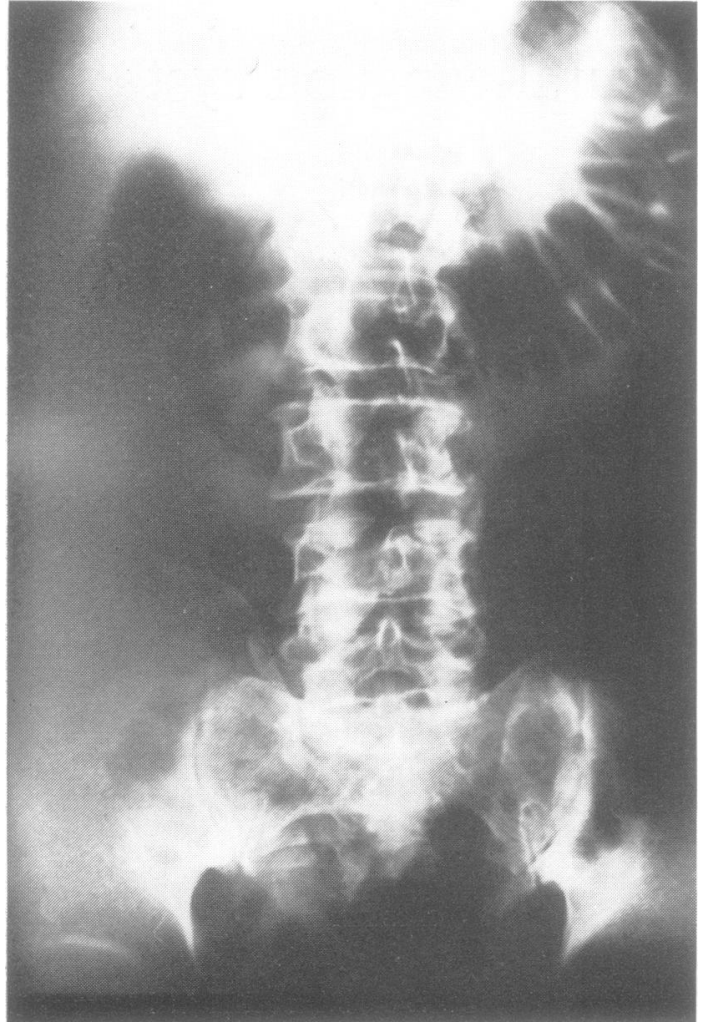

FIG. 1. Mild rotoscoliosis of the lumbar spine with the convexity to the right. Moderate spondylotic changes along the left lateral margins of the vertebral bodies throughout the mid and lower lumbar levels.

at the beginning of the examination. With any change of position, the patient suffered very severe pain in the back with radiation to the left lower extremity.

Marked paravertebral muscle spasm was found in the lumbar area, more pronounced on the right than on the left side. The mobility of the lower back was limited in all directions, but this was most pronounced in dorsiflexion and flexion to the left. Both of these movements exacerbated the patient's pain with radiation to the left hallux. Straight leg raising was normal on the right but on the left it was limited to 70 degrees with radiation of pain along the posterior aspect of the left thigh and lateral aspect of the left leg with numbness of the left hallux. The knee jerks were brisk and symmetrical. The ankle jerks were moderate and symmetrical. The plantar reflexes showed downgoing toes. There was moderate

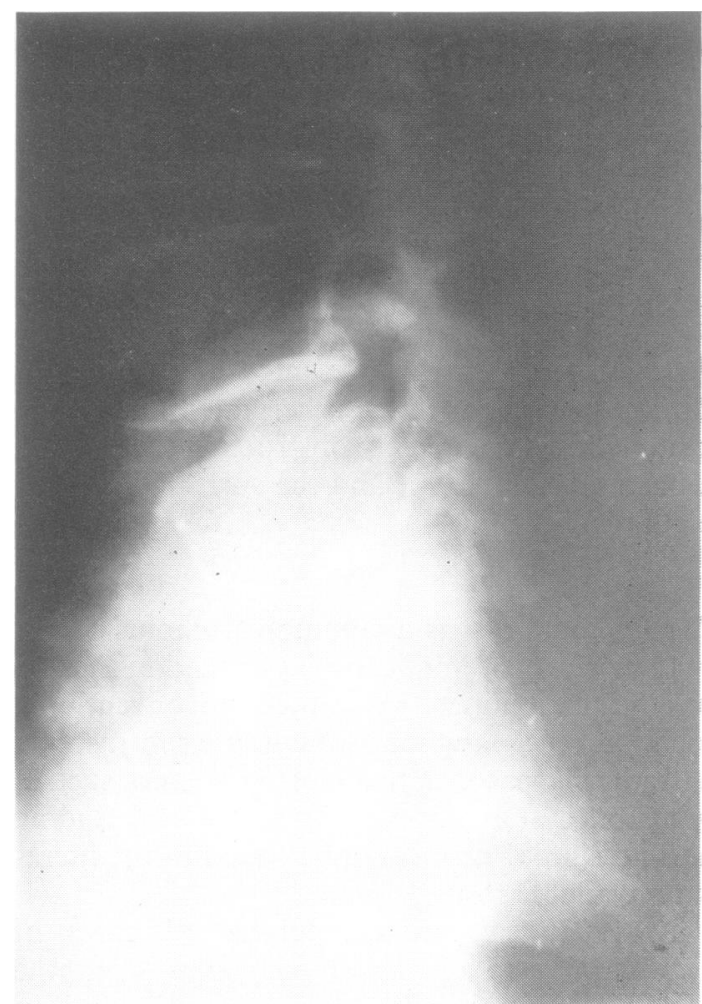

FIG. 2. Scalloping of the posterior aspect of the bod of $L 4$ vertebra.

weakness of dorsiflexion of the left foot and also mild weakness of dorsiflexion of the right (contralateral) hallux. There was a strip of hypaesthesia on the posterior aspect of the left thigh and on the dorsum of the left hallux. The remainder of the neurological examination was unremarkable, but dorsalis pedis pulses were absent bilaterally.

VDRL in blood and spinal fluid, electrocardiogram, and chest radiographs were normal. The radiographs of the lumbosacral spine showed a mild rotoscoliosis of the lumbar spine with the convexity to the right (Fig. 1). Moderate spondylotic changes were present along the left lateral margins of the vertebral bodies throughout the mid- and lower lumbar levels and some spondylotic changes were also present in the posterior facets. There was scalloping of the posterior aspect of the body of L4 vertebra (Fig. 2).

A Pantopaque myelogram was performed on 8 December 1970 . The needle was introduced at the 


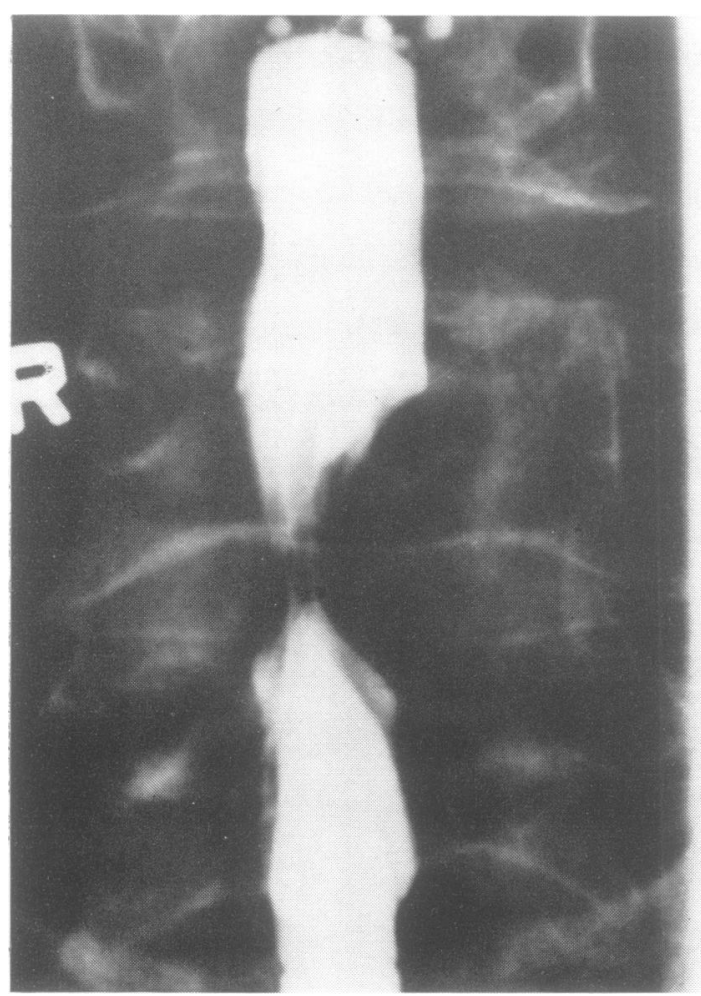

FIG. 3. An extradural defect demonstrated on the $A P$ view of the Pantopaque myelogram.

L2-3 level. The spinal fluid was clear, colourless, contained no cells and $110 \mathrm{mg} / 100 \mathrm{ml}$. protein. Nine $\mathrm{ml}$. Pantopaque were introduced and a round extradural defect was demonstrated on the left side, centred at the L4-5 intervertebral space. The lesion obstructed the flow of Pantopaque almost completely and part of the dye trapped below the lesion could not be retrieved (Figs 3 and 4).

A partial hemilaminectomy of L4 vertebra was performed on 9 December 1970. The lamina was unchanged but the yellow ligament was infiltrated by old dark brown blood. Further exploration revealed a soft black-brown epidural mass. No clear capsule of the lesion could be seen macroscopically. The lesion had produced a small cavity in the left L4 pedicle. There was no infiltration of bone or dura mater. The lesion amounted to about $4 \mathrm{ml}$. and was removed piecemeal after enlarging the laminectomy. Exploration of the L4-5 disc revealed no further abnormality.

After the operation, the pain disappeared. Fluoroscopy performed on 17 December 1970, using the
FIG. 4. The lateral view of the Pantopaque myelogram with the extradural defect at the L4-5 level.

Pantopaque trapped below the mass, showed free movement of the contrast medium.

The microscopic examination of the lesion revealed fragments of non-inflammatory synovium, degenerating bone, and cartilage. The cyst wall was formed by dense fibrous connective tissue with no particular lining (Figs. 5 and 6). The lesion was thought to be a non-neoplastic cystic degenerative process associated with degenerative changes of the intervertebral joint (Dahlin, 1970) - in other words, a ganglion cyst. Localized trauma associated with degenerative changes could explain the bleeding in the surrounding tissue and into the cyst (Dahlin, 1970).

The patient was discharged 12 days after the operation and went back to his work as a heavy equipment operator about $3 \frac{1}{2}$ months after the operation. He has had no pain or episodes of the burning sensation in the scrotum since the operation. 


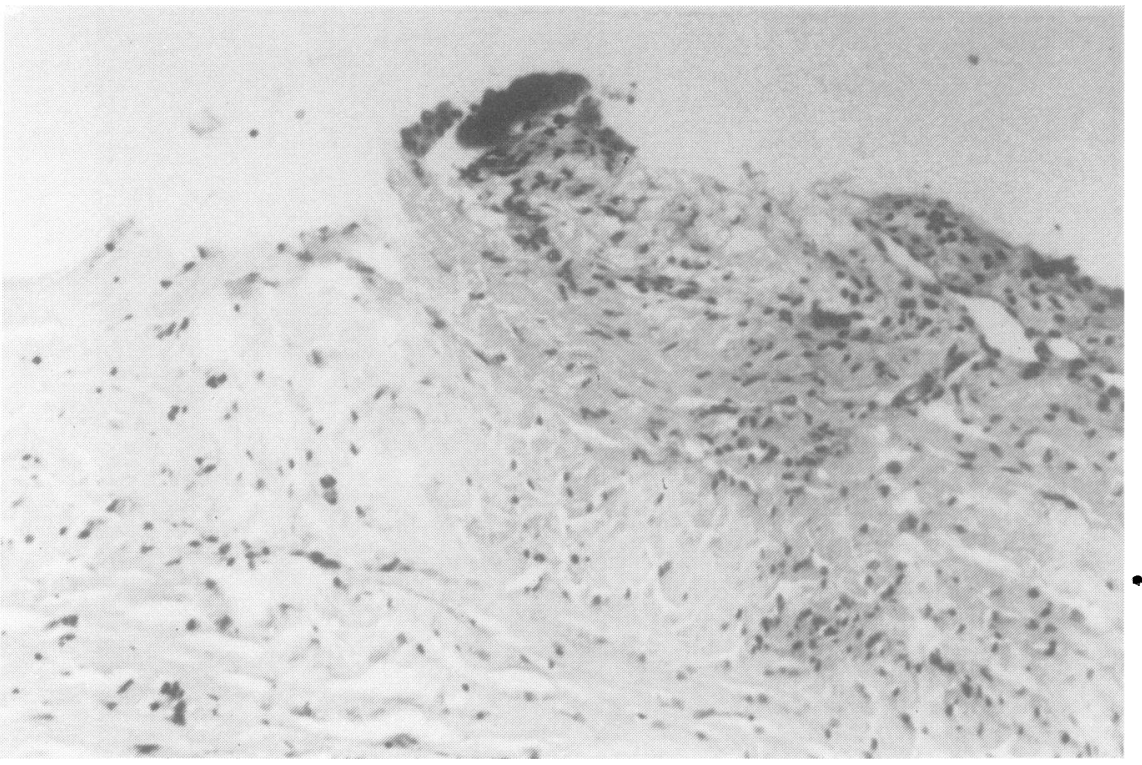

FIG. 5. Sections of the wall of the cyst disclosing no particular lining. Minimal fibrous exudate is noted on the surface of the cyst with a few histiocytes and round cells. Haematoxylin and eosin, $\times 100$.

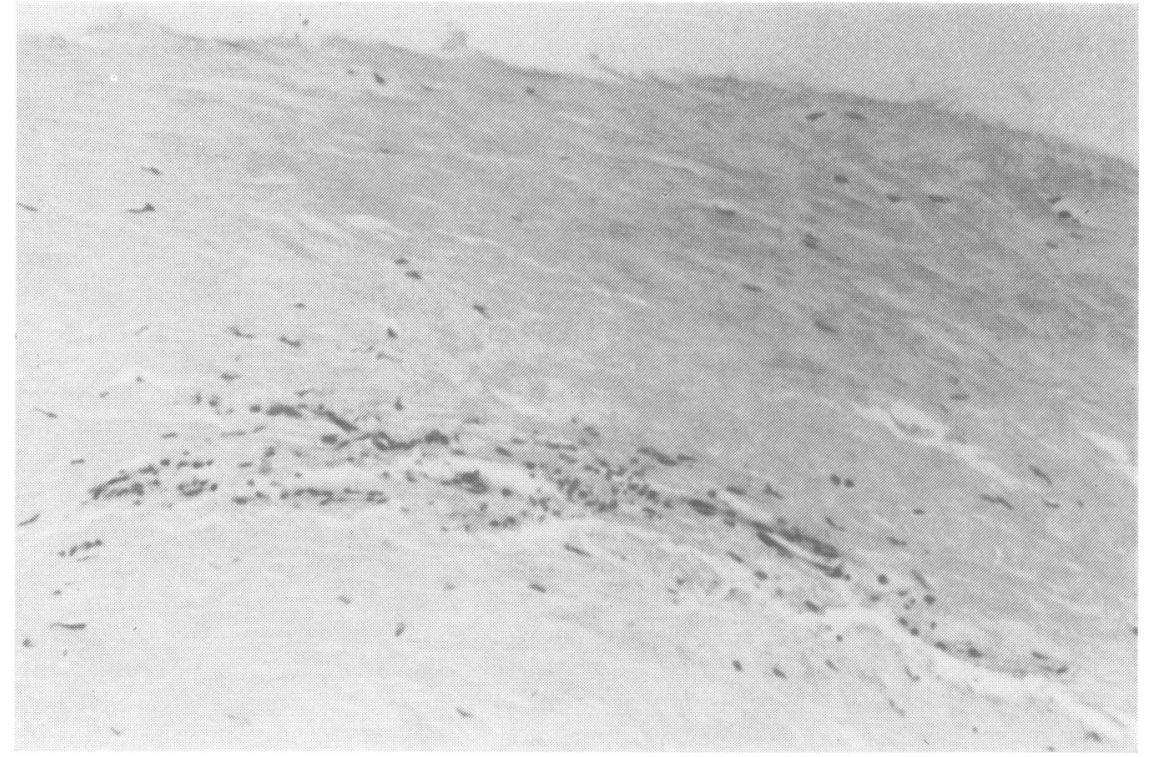

FIG. 6. Most of the wall is formed by almost acellular, degenerated fibrous tissue. Haematoxylin and eosin, $\times 100$. 


\section{DISCUSSION}

The pathogenesis of the cystic ganglion is obscure and according to Barnes, Larsen, and Posch (1964) it is not related to injury in most cases. According to Robbins (1967) most of the lesions arise apparently through a defect in the wall of the joint capsule or tendon sheath. It is, however, difficult to demonstrate a connection between such a cyst and the joint capsule or tendon sheath. Therefore, a possibility exists that the cysts may arise in displaced rests of synovial tissue or by the transformation of primitive connective tissue into synovial cells that then secrete mucin to create the cystic space (Robbins, 1967).

Another explanation of the pathogenesis of development of a ganglion is myxoid degeneration and cystic softening of the collagenous connective tissue of a joint capsule or tendon sheath. A big cyst is created by coalescence of smaller areas of cystic changes (Lichtenstein, 1970).

Johnson, Graham, and Helwig (1965) and Johnson and Helwig (1966) suggest that increased production of hyaluronic acid by fibroblasts due to articular movements may play a role in production of ganglion and myxoid cysts.

In our case, we found bleeding into the lumen of the cyst as well as the surrounding tissue. We assume that trauma may have played a role in exacerbation of the clinical syndrome due to bleeding. The fact that the extent of the movements in the lumbar area is greatest at the L4-5 level (Kraft and Levinthal, 1951) as well as degenerative changes in the area of the cyst, could predispose to bleeding in a patient operating heavy equipment, even with a minor injury.

Even though the clinical picture in our case was suggestive of herniation of the L4-5 nucleus pulposus, other conditions had to be ruled out. A primary or metastatic tumour, an extradural arachnoid cyst, dermoid cyst, a neurofibroma with cystic degeneration (Kao et al., 1968) as well as a sacral nerve root cyst of Tarlov (Tarlov, 1953; Strully, Heiser, 1954; Jacobs, Smith, and Van Horn, 1954) had to be considered. A ganglion cyst, with or without bleeding into it, should be added to the list of possibilities, as illustrated by this case and those of Kao et al. (1968).

\section{REFERENCES}

Barnes, W. E., Larsen, R. D., and Posch, J. L. (1964). Review of ganglia of the hand and wrist with analysis of surgical treatment. Plastic and Reconstructive Surgery, 34, 570-578.

Cloward, R. B., and Bucy, P. C. (1937). Spinal extradural cyst and kyphosis dorsalis juvenilis. American Journal of Roentgenology, 38, 681-706.

Dahlin, D. C. (1970). Mayo Clinic, Rochester, Minnesota. (Personal communication.)

Gortvai, P. (1963). 'Extradural cysts of the spinal canal'. Journal of Neurology, Neurosurgery, and Psychiatry, 26, 223-230.

Jacobs, L. G., Smith, J. K., and Van Horn, P. S. (1954). Myelographic demonstration of cysts of spinal membranes. Radiology, 62, 215-221.

Johnson, W. C., Graham, J. H., and Helwig, E. B. (1965). Cutaneous myxoid cyst. Journal of the American Medical Association, 191, 15-20.

Johnson, W. C., and Helwig, E. B. (1966). Cutaneous focal mucinosis. Archives of Dermatology, 93, 13-20.

Kao, C. C., Uihlein, A., Bickel, W. H., and Soule, E. H. (1968). Lumbar intraspinal extradural ganglion cyst. Journal of Neurosurgery, 29, 168-172.

Kraft, G. L., and Levinthal, D. H. (1951). Facet synovial impingement. Surgery, Gynecology and Obstetrics with International Abstracts of Surgery, 93, 439-443.

Krumbholz, S., Hankowitz, M., and Schyra, B. (1966). Differentialdiagnose extraduraler Zysten im Spinalkanal. Zentralblatt für Neurochirurgie, 27, 118-125.

Lichtenstein, L. (1970). Disease of Bone and Joints. Mosby: St. Louis.

Meredith, J. M. (1940). Unusual tumors and tumor-like lesions of the spinal canal and its contents with special reference to pitfalls in diagnosis. Virginia Medical Monthly, 67, 675-687.

Robbins, S. L. (1967). Pathology. 3rd edn. Saunders: Philadelphia.

Strully, K. J., and Heiser, S. (1954). Lumbar and sacral cysts of meningeal origin. Radiology, 62, 544-549.

Tarlov, I. M. (1953). Sacral Nerve-Root Cysts: Another Cause of the Sciatic or Cauda Equina Syndrome. Thomas: Springfield, IIl. 